Review Article

\title{
Risk of Cardiovascular Events Associated with Inhaled Corticosteroid Treatment in Patients with Chronic Obstructive Pulmonary Disease: A Meta-Analysis
}

\author{
Xia Jing, ${ }^{1}$ Yufeng $\mathrm{Li}^{2}{ }^{2}$ and Jianying $\mathrm{Xu} \mathbb{D}^{1}$ \\ ${ }^{1}$ Department of Respiratory Diseases, Shanxi Dayi Hospital Affiliated to Shanxi Medical University, Taiyuan, Shanxi, China \\ ${ }^{2}$ Department of Neurology, Shanxi Dayi Hospital Affiliated to Shanxi Medical University, Taiyuan, Shanxi, China \\ Correspondence should be addressed to Jianying Xu; 18734583616@163.com
}

Received 27 February 2018; Accepted 27 June 2018; Published 15 July 2018

Academic Editor: Alice M. Turner

Copyright ( 12018 Xia Jing et al. This is an open access article distributed under the Creative Commons Attribution License, which permits unrestricted use, distribution, and reproduction in any medium, provided the original work is properly cited.

\begin{abstract}
Background. The cardiovascular (CV) safety of inhaled corticosteroids (ICSs) in chronic obstructive pulmonary disease (COPD) is controversial because different studies have suggested that ICSs either increase or reduce the risk of CV events in COPD patients. In this meta-analysis, we assess the CV safety of ICS therapy in COPD. Methods. A meta-analysis of randomized, double-blind, parallelgroup, placebo-controlled trials of ICS treatment for COPD that include at least 4 weeks of follow-up was performed. A random-effects model was used to evaluate the effects of ICS treatment on CV events. CV events were documented in each trial, and the relative risk (RR) and 95\% confidence intervals (CIs) for ICSs were estimated. Results. Thirty-one trials were included in this meta-analysis. The risk of CV events was not different between ICS-treated and control groups (RR: 0.99; 95\% CI: 0.93 to 1.06; $P=0.801$ ). In a subgroup analysis, there were no significant differences in CV events between an ICS combined with long-acting $\beta_{2}$ agonist (LABA) (ICS + LABA) group and an LABA-only group (RR: 1.00; 95\% CI: 0.90 to 1.10; $P=0.930$ ), as well as between a combination group (ICS + LABA) and a long-acting muscarinic antagonist (LAMA) combined with LABA (LAMA + LABA) group (RR: 0.78; $95 \%$ CI: 0.39 to $1.55 ; P=0.473$ ). In addition, there was no difference in the risk of CV events between ICS treatment and control groups (RR: $0.99 ; 95 \%$ CI: 0.90 to $1.09 ; P=0.872)$. Conclusions. These results demonstrate that ICSs do not increase the risk of CV events in COPD patients.
\end{abstract}

\section{Introduction}

Chronic obstructive pulmonary disease (COPD) is currently the fourth leading cause of death in the world [1] and is projected to be the third leading cause of death worldwide by 2020 [2]. Inflammatory changes in the airway and lung parenchyma are responsible for pulmonary function decline [3]. Inhaled corticosteroids (ICSs) are effective in reducing airway inflammation, nonspecific airway hyperresponsiveness, and airway obstruction in patients with COPD [4]. An ICS combined with a long-acting $\beta_{2}$ agonist (LABA) is more effective than monotherapy in improving lung function, reducing symptoms, increasing exercise tolerance, decreasing the frequency of exacerbation and hospitalization, and improving patient health [5]. According to the current Global Initiative for Chronic Obstructive Lung Disease (GOLD) guidelines, ICSs in combination with LABAs are suggested for patients with moderate-to-very severe COPD [6]. ICSs, such as fluticasone and budesonide, are widely used in COPD treatment, and other formulations of ICSs approved for use in COPD are fluticasone with salmeterol and budesonide with formoterol [7].

COPD is significantly associated with subclinical atherosclerosis [8], a recognized marker of cardiovascular (CV) disease. CV disease, which is a frequent and important comorbidity in COPD, is a fatal cause of morbidity and mortality among COPD patients during exacerbations [9]. ICSs may potentially reduce CV events by reducing exacerbations, alleviating hypoxia, and relieving the systemic inflammatory reaction to atherogenesis in patients with COPD [10]. Nevertheless, after prolonged treatment, the potential benefits of an ICS may be offset by its adverse 
systemic effects, such as increased extracellular volume, hypertension, glucose intolerance, and dyslipidemia, which are well-recognized risk factors for CV disease [11, 12]. Several studies have shown that ICS treatment can alleviate $\mathrm{CV}$ symptoms in COPD patients [3, 13-15], while other studies have suggested that ICSs lead to an increased risk of $\mathrm{CV}$ events [16, 17]. Critical evaluation is required to assess whether ICS treatment can reduce or increase the risk of CV events in COPD patients. Therefore, we conducted this meta-analysis to evaluate the effect of ICS treatment on CV events in COPD patients compared with controls.

\section{Materials and Methods}

2.1. Register and Search Strategy. This systematic review and meta-analysis were reported in accordance with the Preferred Reporting Items for Systematic Reviews and MetaAnalyses (PRISMA) Statement and registered at the International Prospective Register of Systematic Reviews (number CRD42017066017).

We searched PubMed, Embase, the Cochrane Library, Web of Knowledge, the United States Food and Drug Administration (US FDA) website, the http://ClinicalTrials.gov database, and the GSK (GlaxoSmithKline) Clinical Study Register for eligible trials. The search strategy used for PubMed was "inhaled corticosteroids" OR "ICS" OR "budesonide" OR "fluticasone" OR "flunisolide" OR "beclomethasone" OR "beclometasone" OR "triamcinolone" AND “COPD” OR "chronic obstructive pulmonary disease" OR "chronic obstructive lung disease" OR "COAD" OR "chronic obstructive airway disease" OR "pulmonary disease, chronic obstructive" OR "airflow obstruction, chronic" OR "chronic airflow obstruction" AND "mortality" OR “death" OR "myocardial” OR "cardiovascular" AND "clinical trial," based on previously published meta-analyses $[18,19]$. We also conducted a manual search using the reference lists of key articles published in English. We considered all potentially eligible studies for review, irrespective of the primary outcome or language. Those searches aimed at identifying studies which were published between January 1, 1980, and January 24, 2018.

2.2. Eligibility Criteria. The inclusion criteria for our trials were as follows: (1) studies that were randomized controlled trials (RCTs) with a double-blind, parallel-group, placebocontrolled design and more than 4 weeks of follow-up and the title or abstract including any ICS (flunisolide, fluticasone, beclomethasone, budesonide, or triamcinolone); (2) studies that used standardized diagnostic criteria for COPD (spirometry is required for diagnosis in this clinical context, and the presence of a postbronchodilator FEV1/FVC (forced expiratory volume in the first second/forced vital capacity) ratio $<0.70$ confirms the presence of a persistent airflow limitation, and thus the presence of COPD, in patients with appropriate symptoms and significant exposures to noxious stimuli [20]); (3) studies that included any subtype of COPD, severity of disease, and sex or race of study participant subjects; (4) studies that used an ICS as the intervention drug versus a control treatment, which consisted of an ICS versus placebo, an ICS in combination with an LABA versus an LABA alone, or the combination of an ICS and an LABA versus the combination of a long-acting muscarinic antagonist (LAMA) and an LABA; (5) trials that provided the details of CV events (coronary artery disorders, cardiac arrhythmias, heart failures, cardiac disorder signs and symptoms, myocardial disorders, cardiac valve disorders, pericardial disorders, central nervous system vascular disorders, arteriosclerosis, stenosis, vascular insufficiencies and necrosis, aneurysms and artery dissections, embolisms, thrombosis, and hypertension) and explicitly reported data (including zero events) for at least one such event, but the outcome does not include stroke or peripheral arterial disease. New onset cases of cardiac disorders and cardiovascular death were included; and (6) studies whose full text can be found on a search site.

2.3. Exclusion Criteria. Our exclusion criteria were as follows: (1) studies that were less than 4 weeks in duration, as we were interested in long-term CV event risks; (2) studies that mixed groups of participants with asthma; (3) trials that did not compare an ICS with another treatment; and (4) studies that provided no raw data regarding the number of $\mathrm{CV}$ events in ICS-treated patients with COPD.

2.4. Outcome Measures and Data Extraction. The initial outcomes were CV adverse events. The CV events were defined as coronary artery disorders, cardiac arrhythmias, heart failures, cardiac disorder signs and symptoms, myocardial disorders, cardiac valve disorders, pericardial disorders, central nervous system vascular disorders, hypertension, arteriosclerosis, stenosis, vascular insufficiencies and necrosis, aneurysms and artery dissections, embolisms, and thrombosis. Two reviewers (XJ and YFL) independently and individually extracted the outcome data with an agreement value $(\kappa)$ of $94.5 \%$, and a third reviewer (JYX) provided additional insight when a discrepancy occurred. If the primary outcomes were not available in the original article, we searched for details using http://ClinicalTrials.gov, the US FDA website, and the manufacturer's clinical trial registry website. We used the Jadad scoring system to evaluate all trials [21], and a score $>2$ was required for a trial to be kept in our analysis.

2.5. Statistical Analysis. We pooled trial data using Stata Version 12.0 and calculated the relative risk (RR) and 95\% confidence intervals (CIs) for the primary outcomes. A twosided $\alpha$ value of 0.05 was defined as statistically significant. The magnitude of heterogeneity was estimated by the $I^{2}$ statistic and Cochran's $Q$ test, and an $I^{2}$ value greater than $50 \%$ was indicative of moderate-to-high heterogeneity. If substantial statistical heterogeneity was found, we explored the sources of heterogeneity and the effect of individual study characteristics and subgroups on the risk estimates. The funnel plots and Begg's and Egger's tests were used to assess the publication bias.

Subgroup analyses were conducted with the data separated by three different groups (ICS versus placebo, ICS + LABA versus LABA, and ICS + LABA versus LAMA + LABA). 

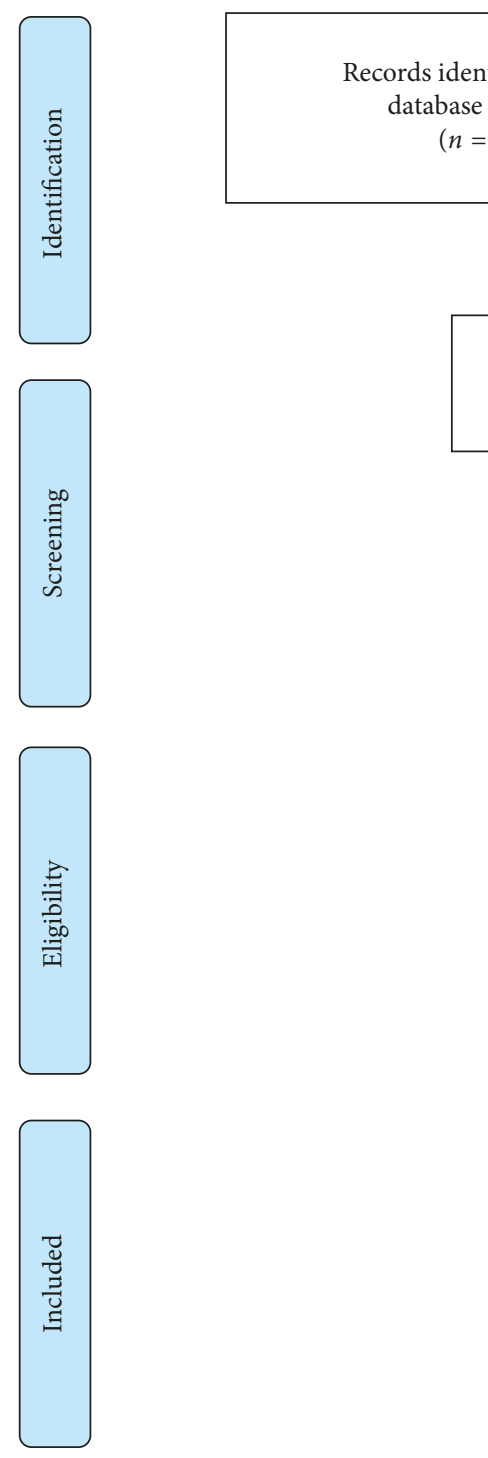
darough $(n=500)$

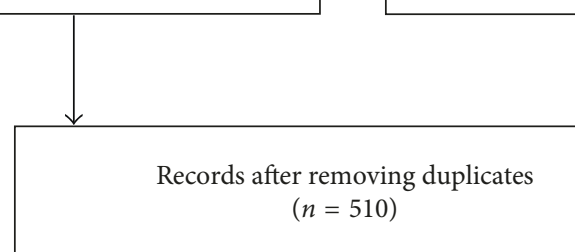
through manual searching $(n=10)$

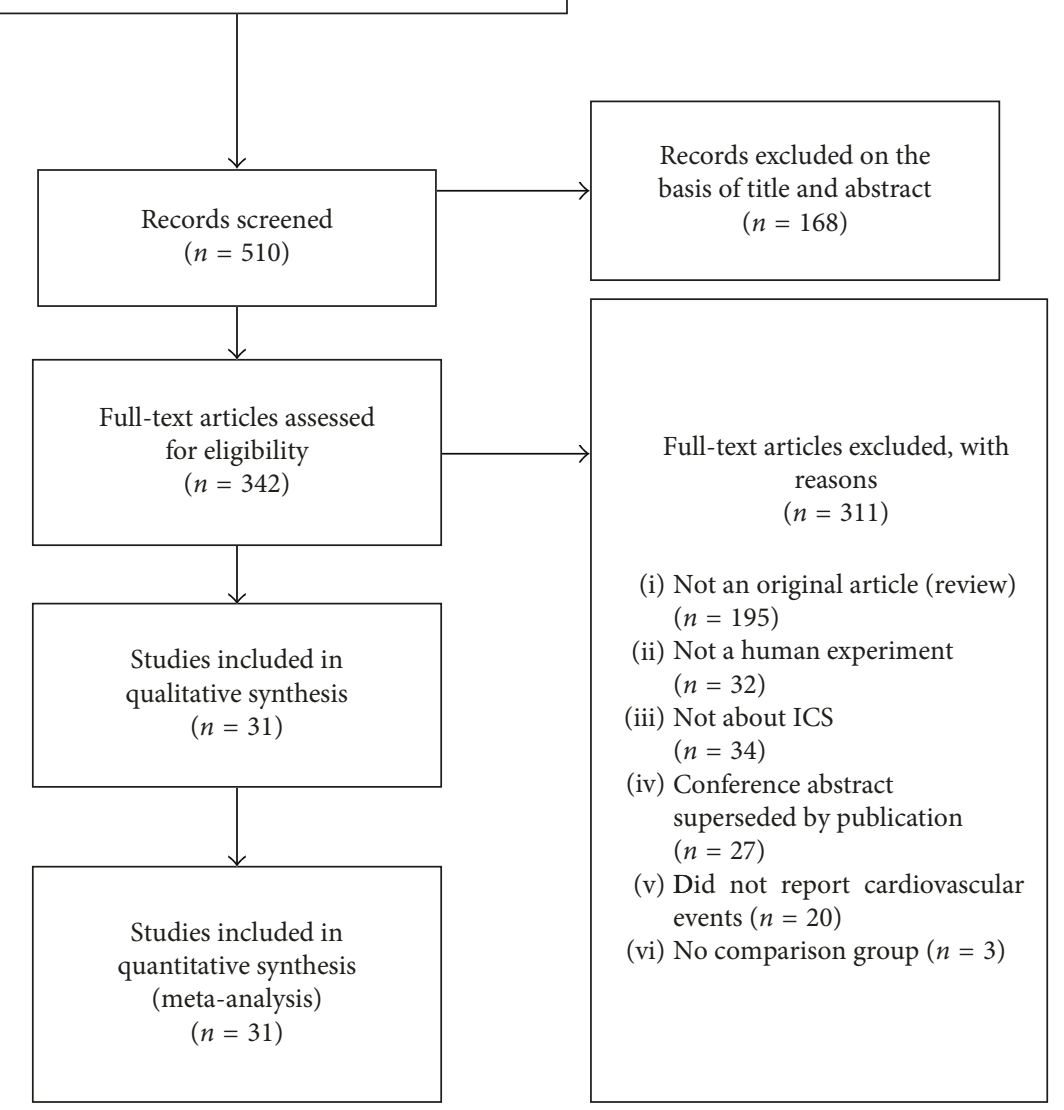

FIgURE 1: Study selection process.

An influence analysis was performed to evaluate the influence of individual studies on the summary effect. Because the effect of ICS on CV disease is a long-term effect, we conducted a sensitive analysis including studies with longerterm follow-up ( $>2$ years).

\section{Results}

3.1. Characteristics of the Identified Studies. A total of 31 trials including 57031 patients fulfilled the inclusion criteria and were selected for analysis. The details of the study selection strategy are shown in Figure 1, and the main characteristics of the included trials are shown in Table 1. All trials were of high quality (Jadad score $>2$ ). These trials enrolled a total of 29171 participants who received an ICS and 27860 participants who received control therapies. Among the 31 studies, the main outcome of 13 studies was cardiovascular events, but there was no exact definition of cardiovascular events in these studies. In 31 studies, 5 studies resulted in cardiac arrhythmias, 2 in atrial fibrillation, 3 in cardiac failure, 3 in cardiac ischemia, 1 in acute myocardial infarction, 1 in angina pectoris, 1 in coronary artery stenosis, 1 in acute coronary syndrome, 2 in hypertension, and 15 in cardiovascular death. Inhaled fluticasone was evaluated in 26 trials [3, 16, 17, 22-44], inhaled budesonide in 4 trials [15, 45-47], and inhaled beclomethasone in only 1 trial [48]. The range of mean age in patients was from 52.4 to 67.6 . The majority of the participants were male, with the proportion of current smokers ranging from $24 \%$ [22] to $83 \%$ [31]. The duration of the trials ranged from 4 to 156 weeks, with 18 trials being longer than 52 weeks in duration [3, 15, 22-26, 28, 30, 32, 33, 35, 39, 42, 44, 45, 47]. Most trials enrolled participants with severe COPD, as the mean predicted FEV1 of the participants was $>50 \%$ in 7 trials $[15,23,29,33,37$, 38 , 47] compared to $\leq 50 \%$ in 17 trials $[3,16,17,22,24,28$, 
TABLE 1: Characteristics of included studies.

\begin{tabular}{|c|c|c|c|c|c|c|c|c|}
\hline Author & Year & $\mathrm{J}$ & Drug & Male (\%) & $\begin{array}{c}\text { Mean } \\
\text { age (years) }\end{array}$ & $\begin{array}{c}\text { FEV1 } \\
(\% \text { predicted })\end{array}$ & $\begin{array}{c}\text { Current } \\
\text { smokers (\%) }\end{array}$ & $\begin{array}{c}\text { Treatment } \\
\text { duration } \\
\text { (weeks) }\end{array}$ \\
\hline Aaron et al. [22] & 2007 & 7 & SFC versus SAL & $\begin{array}{l}57.9 \\
57.4\end{array}$ & $\begin{array}{l}67.5 \pm 8.9 \\
67.6 \pm 8.2\end{array}$ & $\begin{array}{l}39.4 \pm 11.9 \\
38.0 \pm 13.1\end{array}$ & $\begin{array}{l}32.4 \\
24.3\end{array}$ & 52 \\
\hline Burge et al. [23] & 2000 & 5 & FP versus placebo & $\begin{array}{c}75 \\
74.2\end{array}$ & $\begin{array}{l}63.7 \pm 7.1 \\
63.8 \pm 7.1\end{array}$ & $\begin{array}{l}50.3 \pm 14.9 \\
50.0 \pm 14.9\end{array}$ & $\begin{array}{l}36.4 \\
39.2\end{array}$ & 156 \\
\hline Calverley et al. [24] & 2003 & 5 & $\begin{array}{l}\text { SFC versus SAL; FP } \\
\text { versus placebo }\end{array}$ & $\begin{array}{l}75 \\
70 \\
70 \\
75 \\
75\end{array}$ & $\begin{array}{l}62.7 \pm 8.7 \\
63.2 \pm 8.6 \\
63.5 \pm 8.5 \\
63.4 \pm 8.6\end{array}$ & $\begin{array}{c}44.8 \pm 14.7 \\
44.3 \pm 13.8 \\
45 \pm 13.6 \\
44.2 \pm 13.7\end{array}$ & $\begin{array}{l}52 \\
51 \\
53 \\
47\end{array}$ & 52 \\
\hline Calverley et al. [25] & 2007 & 6 & $\begin{array}{l}\text { SFC versus SAL; FP } \\
\text { versus placebo }\end{array}$ & $\begin{array}{l}75 \\
76 \\
75 \\
76\end{array}$ & $\begin{array}{c}65 \pm 8.3 \\
65.1 \pm 8.2 \\
65 \pm 8.4 \\
65 \pm 8.2\end{array}$ & $\begin{array}{l}44.3 \pm 12.3 \\
43.6 \pm 12.6 \\
44.1 \pm 12.3 \\
44.1 \pm 12.3\end{array}$ & $\begin{array}{l}43 \\
43 \\
43 \\
43\end{array}$ & 156 \\
\hline Ferguson et al. [26] & 2008 & 7 & SFC versus SAL & $\begin{array}{l}58.3 \\
52.0\end{array}$ & $\begin{array}{l}64.9 \pm 9.0 \\
65.0 \pm 9.1\end{array}$ & $\begin{array}{l}39.8 \pm 13.9 \\
50.6 \pm 15.4\end{array}$ & $\begin{array}{l}40 \\
38\end{array}$ & 52 \\
\hline FLTA3025 [41] & 2000 & 5 & FP versus placebo & $\begin{array}{l}66 \\
72\end{array}$ & $\begin{array}{l}63.3 \pm 10 \\
65.2 \pm 8.7\end{array}$ & NA & NA & 24 \\
\hline Hanania et al. [27] & 2003 & 7 & SFC versus SAL & $\begin{array}{l}61 \\
58\end{array}$ & $\begin{array}{l}63 \pm \mathrm{NA} \\
64 \pm \mathrm{NA}\end{array}$ & $\begin{array}{l}41 \pm 11 \\
42 \pm 12\end{array}$ & $\begin{array}{l}43 \\
51\end{array}$ & 24 \\
\hline Kardos et al. [28] & 2007 & 4 & SFC versus SAL & $\begin{array}{c}74 \\
77.6\end{array}$ & $\begin{array}{c}63.8 \pm 8.3 \\
64 \pm 8.2\end{array}$ & $\begin{array}{l}40.4 \pm 8.9 \\
40.3 \pm 8.5\end{array}$ & $\begin{array}{l}49.7 \\
49.9\end{array}$ & 52 \\
\hline Lofdahl et al. [15] & 2007 & 5 & $\begin{array}{l}\text { Budesonide versus } \\
\text { placebo }\end{array}$ & $\begin{array}{l}73.5 \\
72.2\end{array}$ & $\begin{array}{l}52.5 \pm 7.5 \\
52.4 \pm 7.7\end{array}$ & $\begin{array}{l}76.8 \pm 12.4 \\
76.9 \pm 13.2\end{array}$ & $\begin{array}{l}39.4 \\
39.2\end{array}$ & 156 \\
\hline Paggiaro et al. [29] & 1998 & 5 & FP versus placebo & $\begin{array}{l}99 \\
78\end{array}$ & $\begin{array}{l}62 \pm \mathrm{NA} \\
64 \pm \mathrm{NA}\end{array}$ & $\begin{array}{l}59 \pm 18 \\
55 \pm 17\end{array}$ & $\begin{array}{l}49 \\
49\end{array}$ & 24 \\
\hline Rennard et al. [45] & 2009 & 6 & $\begin{array}{l}\text { Budesonide/FOR versus } \\
\text { placebo }\end{array}$ & $\begin{array}{l}62.5 \\
65.3\end{array}$ & $\begin{array}{l}63.2 \pm 8.9 \\
62.9 \pm 9.1\end{array}$ & $\begin{array}{l}33.8 \pm 11.4 \\
35.5 \pm 11.9\end{array}$ & $\begin{array}{l}34.8 \\
39.5\end{array}$ & 52 \\
\hline SCO100250 [40] & 2007 & 6 & SFC versus SAL & $\begin{array}{l}51 \\
57\end{array}$ & $\begin{array}{l}65.4 \pm \mathrm{NA} \\
65.3 \pm \mathrm{NA}\end{array}$ & NA & NA & 52 \\
\hline SCO100470 [42] & 2005 & 6 & SFC versus SAL & $\begin{array}{l}78.3 \\
77.2\end{array}$ & $\begin{array}{l}63.5 \pm 9.3 \\
63.7 \pm 9.0\end{array}$ & NA & $\begin{array}{l}42 \\
44\end{array}$ & 24 \\
\hline SCO40041 [43] & 2007 & 5 & SFC versus SAL & $\begin{array}{l}59.7 \\
62.7\end{array}$ & $\begin{array}{l}65.4 \pm 8.4 \\
65.9 \pm 9.5\end{array}$ & NA & NA & 156 \\
\hline SFCT01/SCO30002 [44] & 2005 & 5 & FP versus placebo & $\begin{array}{c}83.9 \\
80\end{array}$ & $\begin{array}{l}64.6 \pm 8.7 \\
65.7 \pm 9.0\end{array}$ & NA & NA & 52 \\
\hline Tashkin et al. [46] & 2008 & 4 & $\begin{array}{c}\text { Budesonide/FOR versus } \\
\text { FOR } \\
\text { Budesonide versus } \\
\text { placebo }\end{array}$ & $\begin{array}{l}67.9 \\
65.5 \\
67.6 \\
69.0\end{array}$ & $\begin{array}{l}63 \pm \mathrm{NA} \\
64 \pm \mathrm{NA} \\
63 \pm \mathrm{NA} \\
63 \pm \mathrm{NA}\end{array}$ & $\begin{array}{l}33.7 \pm 11.8 \\
33.6 \pm 11.3 \\
33.5 \pm 10.8 \\
34.6 \pm 10.5\end{array}$ & $\begin{array}{l}40.8 \\
38.4 \\
40.0 \\
36.0\end{array}$ & 26 \\
\hline Vestbo et al. [47] & 1999 & 5 & $\begin{array}{l}\text { Budesonide versus } \\
\text { placebo }\end{array}$ & $\begin{array}{l}58.6 \\
62.1\end{array}$ & $\begin{array}{l}59.0 \pm 8.3 \\
59.1 \pm 9.7\end{array}$ & $\begin{array}{l}86.2 \pm 20.6 \\
86.9 \pm 21.1\end{array}$ & $\begin{array}{l}75.9 \\
77.2\end{array}$ & 156 \\
\hline Wouters et al. [30] & 2005 & 4 & SFC versus SAL & $\begin{array}{l}73 \\
75\end{array}$ & $\begin{array}{l}63 \pm 7.9 \\
64 \pm 7.7\end{array}$ & $\begin{array}{l}47.4 \pm 13.9 \\
48.2 \pm 12.9\end{array}$ & $\begin{array}{l}39 \\
35\end{array}$ & 52 \\
\hline Boscia et al. [31] & 2012 & 4 & FF/VI versus placebo & 46 & $57.9 \pm 9.2$ & $49.8 \pm 10.6$ & 83 & 4 \\
\hline Vestbo et al. [32] & 2009 & 4 & $\begin{array}{l}\text { FP versus placebo } \\
\text { SFC versus SAL }\end{array}$ & $\begin{array}{l}75 \\
77 \\
75 \\
77\end{array}$ & $\begin{array}{l}64.8 \pm \mathrm{NA} \\
64.9 \pm \mathrm{NA} \\
64.9 \pm \mathrm{NA} \\
64.8 \pm \mathrm{NA}\end{array}$ & $\begin{array}{l}44.7 \pm \mathrm{NA} \\
44.4 \pm \mathrm{NA} \\
44.8 \pm \mathrm{NA} \\
44.1 \pm \mathrm{NA}\end{array}$ & $\begin{array}{l}43 \\
42 \\
43 \\
43\end{array}$ & 144 \\
\hline Vestbo et al. [39] & 2016 & 6 & $\begin{array}{l}\text { FF versus placebo } \\
\text { FF/VI versus VI }\end{array}$ & $\begin{array}{l}74 \\
75 \\
76 \\
75\end{array}$ & $\begin{array}{l}65 \pm 8 \\
65 \pm 8 \\
65 \pm 8 \\
65 \pm 8\end{array}$ & $\begin{array}{l}59.6 \pm 6.1 \\
59.7 \pm 6.1 \\
59.7 \pm 6.1 \\
59.7 \pm 6.1\end{array}$ & $\begin{array}{l}47 \\
47 \\
45 \\
47\end{array}$ & 152 \\
\hline Kerwin et al. [34] & 2013 & 4 & FF versus placebo & $\begin{array}{l}64 \\
68 \\
67 \\
68\end{array}$ & $\begin{array}{l}62.7 \pm 9.5 \\
62.1 \pm 8.8 \\
62.3 \pm 8.5 \\
63.4 \pm 9.6\end{array}$ & $\begin{array}{l}41.5 \pm 13.13 \\
42.4 \pm 12.80 \\
42.3 \pm 12.74 \\
44.5 \pm 12.78\end{array}$ & $\begin{array}{l}54 \\
54 \\
54 \\
54\end{array}$ & 24 \\
\hline Dransfield et al. [3] & 2013 & 6 & $\mathrm{FF} / \mathrm{VI}$ versus $\mathrm{VI}$ & $\begin{array}{l}57.3 \\
58.4\end{array}$ & $\begin{array}{l}63.6 \pm 9.1 \\
63.6 \pm 9.4\end{array}$ & $\begin{array}{l}45.7 \pm 12.9 \\
44.3 \pm 13.2\end{array}$ & NA & 52 \\
\hline
\end{tabular}


TABLE 1: Continued.

\begin{tabular}{|c|c|c|c|c|c|c|c|c|}
\hline Author & Year & $\mathrm{J}$ & Drug & Male (\%) & $\begin{array}{c}\text { Mean } \\
\text { age (years) }\end{array}$ & $\begin{array}{c}\text { FEV1 } \\
\text { (\% predicted) }\end{array}$ & $\begin{array}{c}\text { Current } \\
\text { smokers (\%) }\end{array}$ & $\begin{array}{c}\text { Treatment } \\
\text { duration } \\
\text { (weeks) }\end{array}$ \\
\hline Calverley et al. [35] & 2010 & 7 & $\begin{array}{l}\text { SFC versus SAL } \\
\text { FP versus placebo }\end{array}$ & $\begin{array}{l}75 \\
76 \\
75 \\
76\end{array}$ & $\begin{array}{l}65.0 \pm 8.3 \\
65.2 \pm 8.2 \\
65.1 \pm 8.4 \\
65.1 \pm 8.1\end{array}$ & NA & $\begin{array}{l}43 \\
43 \\
43 \\
43\end{array}$ & 144 \\
\hline Martinez et al. [16] & 2013 & 5 & $\begin{array}{l}\text { FF/VI versus VI } \\
\text { FF versus placebo }\end{array}$ & $\begin{array}{l}71 \\
74 \\
74 \\
74\end{array}$ & $\begin{array}{l}61.9 \pm 8.8 \\
61.2 \pm 8.6 \\
61.8 \pm 8.3 \\
61.9 \pm 8.1\end{array}$ & $\begin{array}{l}48.1 \pm 12.85 \\
48.5 \pm 12.89 \\
48.4 \pm 12.17 \\
48.3 \pm 12.71\end{array}$ & $\begin{array}{l}53 \\
55 \\
56 \\
53\end{array}$ & 24 \\
\hline Donohue et al. [36] & 2015 & 5 & FSC versus UMEC/VI & $\begin{array}{l}69 \\
72\end{array}$ & $\begin{array}{l}63.0 \pm 8.91 \\
62.5 \pm 9.05\end{array}$ & $\begin{array}{l}48.3 \pm 10.82 \\
48.6 \pm 10.71\end{array}$ & $\begin{array}{l}41 \\
45\end{array}$ & 12 \\
\hline Singh et al. [37] & 2015 & 4 & FSC versus UMEC/VI & $\begin{array}{l}71 \\
73\end{array}$ & $\begin{array}{l}61.4 \pm 8.06 \\
61.8 \pm 7.94\end{array}$ & $\begin{array}{l}51.1 \pm 10.50 \\
50.2 \pm 10.85\end{array}$ & $\begin{array}{l}61 \\
57\end{array}$ & 12 \\
\hline Zheng et al. [17] & 2015 & 5 & FF/VI versus placebo & $\begin{array}{l}93 \\
90\end{array}$ & $\begin{array}{l}65.1 \pm 9.19 \\
64.7 \pm 8.78\end{array}$ & $\begin{array}{l}49.6 \pm 13.19 \\
48.6 \pm 13.39\end{array}$ & $\begin{array}{l}52 \\
56\end{array}$ & 24 \\
\hline Wedzicha et al. [48] & 2014 & 5 & $\mathrm{BDP} / \mathrm{FOR}$ versus $\mathrm{FOR}$ & $\begin{array}{l}69 \\
69\end{array}$ & $\begin{array}{l}64.6 \pm 8.6 \\
63.9 \pm 8.6\end{array}$ & $\begin{array}{l}41.9 \pm 6.0 \\
41.6 \pm 6.0\end{array}$ & $\begin{array}{l}39 \\
40\end{array}$ & 48 \\
\hline Vogelmeier et al. [38] & 2013 & 7 & SFC versus QVA149 & $\begin{array}{l}71.6 \\
70.2\end{array}$ & $\begin{array}{l}63.4 \pm 7.7 \\
63.2 \pm 8.2\end{array}$ & $\begin{array}{l}60.0 \pm 10.7 \\
60.5 \pm 10.5\end{array}$ & $\begin{array}{l}48.1 \\
47.7\end{array}$ & 48 \\
\hline Vestbo et al. [33] & 2016 & 7 & FF/VI versus placebo & $\begin{array}{l}50 \\
48\end{array}$ & $\begin{array}{l}67 \pm 10 \\
67 \pm 10\end{array}$ & NA & $\begin{array}{l}45 \\
47\end{array}$ & 144 \\
\hline
\end{tabular}

The quality (Q) of each study was based on the Jadad scoring system. J: Jadad score; FP: fluticasone propionate; SAL: salmeterol xinafoate; SFC: combination of salmeterol xinafoate and fluticasone propionate; BDP: beclomethasone dipropionate; FOR: formoterol; TIO: tiotropium; UMEC: umeclidinium; QVA149: combination of indacaterol (a long-acting $\beta_{2}$ agonist) with glycopyrronium (a long-acting muscarinic antagonist) as a dual bronchodilator; FF: fluticasone furoate; VI: vilanterol; NA: not applicable.

$30-32,34,36,45,46,48]$, whereas 7 trials did not report the details of FEV1.

The modified Jadad scale is used to assess the methodological quality of a clinical trial judging the effectiveness of blinding. The score range is from zero (very poor) to seven (rigorous).

3.2. Main Findings. In total, all 31 studies reported at least one CV event. The ICS treatment did not increase the risk of CV events in COPD patients compared with the controls (RR: $0.99 ; 95 \%$ CI: 0.93 to $1.06 ; P=0.801$; Figure 2), and there was no evidence of statistical heterogeneity $\left(I^{2}=0 \%\right.$, $P=0.846)$.

3.3. Subgroup Analyses. ICS use was not associated with a significant effect on the risk of $\mathrm{CV}$ events when used in the combination of ICS + LABA compared to LABA alone (RR: 1.00 ; $95 \% \mathrm{CI}$ : 0.90 to $1.10 ; P=0.930$ (Figure 2 ); $I^{2}=0 \%$, $P=0.643$ ). In addition, there was no significant difference between the ICS + LABA combination and the LAMA + LABA combination in the number of CV events (RR: $0.78 ; 95 \%$ CI: 0.39 to $1.55 ; P=0.473$ (Figure 2 ); $I^{2}=0 \%, P=0.238$ ). ICS treatment did not increase the risk of CV events compared with placebo (RR: $0.99 ; 95 \% \mathrm{CI}: 0.90$ to $1.09 ; P=0.872$ (Figure 2); $I^{2}=0 \%, P=0.816$ ).

3.4. Sensitivity Analysis. We implemented a sensitivity analysis by using influence analysis to verify whether an individual study influenced the results, and no combined outcomes were changed by any given study. In analysis including studies with a longer-term period ( $>2$ years), the pooled RR and 95\% CI were 0.99 (0.92-1.06), and there was no evidence of statistical heterogeneity either $\left(I^{2}=0 \%\right.$, $P=0.787)$.

3.5. Publication Bias. Moreover, the funnel plot that was used to assess publication bias appeared to be symmetrical and showed no publication bias (Figure 3). Meanwhile, there was no publication bias shown using Egger's test $(P=0.733)$. In sensitivity analysis, there was no publication bias shown using Egger's test either $(P=0.735)$.

\section{Discussion}

Our meta-analysis did not show any consistent association between ICS therapy and CV events in COPD patients, either as monotherapy or in combination with LABAs, when compared to placebo, LABA, and LABA/LAMA controls.

COPD is not simply a pulmonary disease [49]; it is associated with increased extrapulmonary complications. COPD often coexists with other chronic diseases that can influence patients' physical status and prognosis [50]. Patients with COPD are at higher risk of CV events than agematched and sex-matched individuals without COPD $[9,51]$. Meanwhile, more patients with COPD die from CV events than from the respiratory consequences of airflow limitation [52] because the hypoxemia, respiratory alkalosis caused by hyperventilation, and inflammation in people with lung function decline could result in higher $\mathrm{CV}$ morbidity and mortality [53]. In contrast, prevention and 


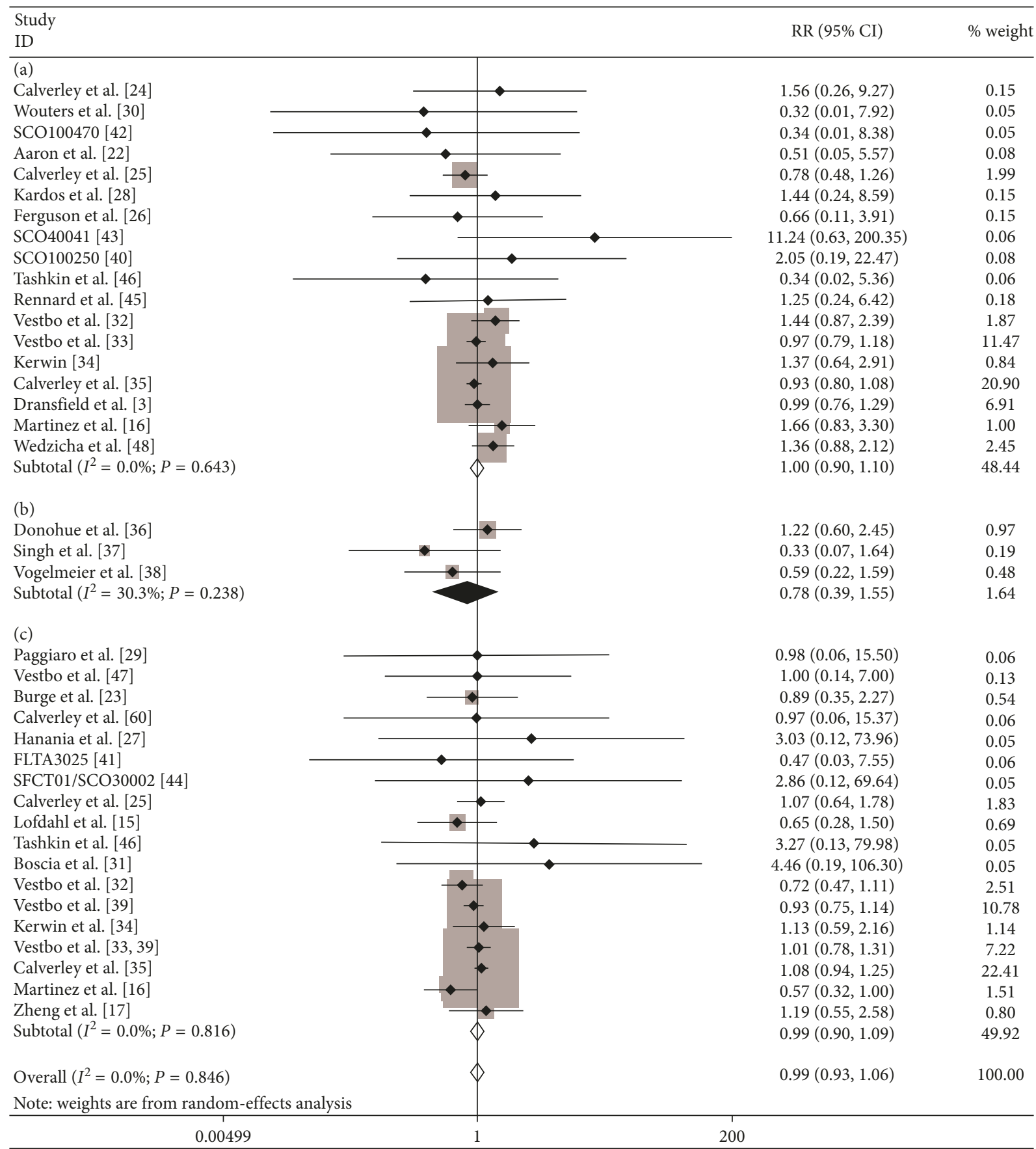

FIGURE 2: Meta-analysis of RCTs of ICSs versus controls for risk of CV events. (a) ICS + LABA versus LABA; (b) ICS + LABA versus LAMA +LABA; (c) ICS versus placebo. LABA: long-acting $\beta_{2}$ agonist; LAMA: long-acting muscarinic agonist.

treatment of exacerbations have been identified by GOLD as a priority since they are associated with impaired pulmonary function. Consequently, treatments that increase lung function and reduce exacerbations [54] would be expected to reduce both respiratory and adverse $\mathrm{CV}$ events. The recommendation of ICS therapy combined with an LABA in patients with moderate-to-very severe airflow limitations is based on evidence for reduced exacerbations. The pathophysiology of COPD includes systemic inflammation disorder and/or alterations in repair mechanisms. There are potential mechanisms linking COPD with an increased risk of CV events, including common risk factors (e.g., smoking), systemic inflammation [55], and vascular dysfunction [56]. The overexpression of inflammatory mediators into the circulatory system of COPD patients is relevant to the progression of CV events [57]. A mechanism for the reduction in CV-related deaths associated with ICS therapy is not clear. Potential explanations include a reduction in COPD exacerbations, which lead to hypoxia and instability that may predispose patients to $\mathrm{CV}$ events, a reduction in systemic inflammatory reactions to atherosclerosis [58], or a reduction in adaptive immune responses. Nevertheless, 


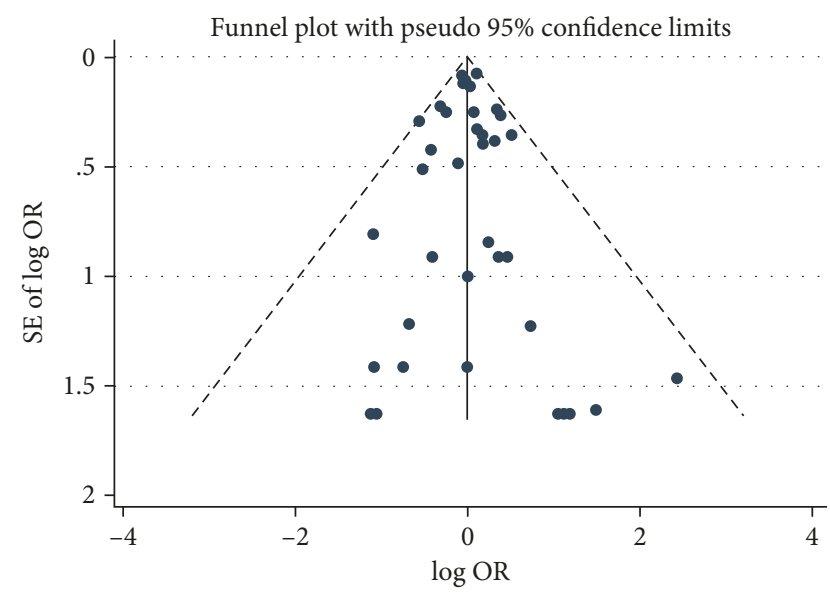

FIGURE 3: Funnel plots of RCTs of ICSs versus controls for risk of CV events.

ICS therapy may have limited CV benefits because ICS treatment does not reduce the inflammatory marker levels in systemic circulation (serum levels of C-reactive protein or interleukin 6), and ICS therapy also has little impact on neutrophil inflammatory responses or extracellular matrix remodeling linked to CV disease in COPD [57, 59].

The results of our analysis are consistent with other published studies showing that ICSs have no increased risks of CV events in COPD patients. Calverley et al. [60] reported that most of the deaths were events related to COPD, and only a few were related to $\mathrm{CV}$ events in COPD patients treated with budesonide. Furthermore, Calverley et al. [35] observed that the probability of COPD patients having an adverse CV event within 3 years of treatment was $24.3 \%$ for fluticasone propionate (FP) and $24.2 \%$ for placebo. Moreover, Dransfield et al. [3] reported that different doses of fluticasone furoate/vilanterol (FF/VI) combinations did not increase the risk of $\mathrm{CV}$ events compared with the risk associated with vilanterol (VI) alone. In addition, Loke et al. [61] concluded that ICS use was not associated with a significant risk of myocardial infarction when combined ICS + LABA therapy was compared to LABA treatment alone (RR: 0.92; 95\% CI: 0.63 to $1.35 ; P=0.67)$ or when ICS treatment was compared to placebo (RR: $0.97 ; 95 \% \mathrm{CI}: 0.67$ to 1.40 ; $P=0.87)$. They also found that ICS use was not associated with a significant risk of $\mathrm{CV}$-related death when combined ICS + LABA therapy was compared to LABA treatment alone (RR: $1.12 ; 95 \%$ CI: 0.79 to $1.58 ; P=0.53$ ) or when ICS was evaluated against placebo (RR: 0.95 ; $95 \%$ CI: 0.71 to 1.27 ; $P=0.74)$. According to a recent study, the CV endpoint in the fluticasone furoate (FF) (hazard ratio (HR): 0.90; 95\% CI: 0.73 to 1.1 ) groups did not differ from that in the placebo group [33]. Meanwhile, FF/VI had no effect on composite CV events (HR: 0.93 ; 95\% CI: 0.75 to 1.14 ) with similar findings for VI (HR: 0.99; 95\% CI: 0.80 to 1.22 ) [33].

There are certain discrepancies between the results of our meta-analysis and the outcomes of previous studies. A number of studies have suggested that ICSs may potentially confer CV benefits. Two observational studies [13, 14] reported a significant association between ICS exposure and a reduction in $\mathrm{CV}$-related deaths but did not specify details on the causes of death. Macie et al. [14] concluded that an ICS-induced reduction in mortality was particularly notable for CV-associated deaths but not for COPD. Lee et al. [13] found that ICS exposure was associated with a $20 \%$ decrease in the odds of a CV-related death (odds ratio (OR): 0.80; 95\% CI: 0.72 to 0.88$)$. A pooled analysis of these two studies showed a significant reduction in $\mathrm{CV}$-associated deaths (RR: 0.79; 95\% CI: 0.72 to $0.86 ; P<0.0001$ ) [61]. Similar beneficial effects were also verified in RCTs. Lofdahl et al. [15] found that patients treated with inhaled budesonide had a significantly lower incidence of ischemic cardiac events (RR: 0.58; 95\% CI: 0.35 to $0.98 ; P=0.043$ ) than those receiving placebo. Additionally, in a previous study [3], the risk of $\mathrm{CV}$ events decreased with increasing doses of FF; specifically, there was a CV benefit of FF/VI therapy compared with VI therapy alone with respect to patient-reported outcomes. Nevertheless, ICSs were not associated with a significantly reduced risk of myocardial infarction (RR: 0.83; 95\% CI: 0.63 to 1.08) in an observational study [62]. Furthermore, another analysis conducted by Calverley et al. [25] showed that there was no significant reduction in cardiac disorders among patients treated with fluticasone (reported as $\mathrm{CV}$ event rates per study year: 0.113 in the placebo group, 0.102 in the fluticasone group, 0.114 in the salmeterol group, and 0.087 in the combination therapy group). Conversely, another study [16] suggested that FF/VI treatment resulted in increased CV effects compared with VI treatment alone. Similarly, in a study of Asian patients treated with FF/VI, high-dose FF was associated with increased $\mathrm{CV}$ events compared to those with low-dose FF [17].

There are several limitations to our research that make it difficult to reach a definitive conclusion. First, the RCTs did not use specific definitions of a CV event, and inconsistent adverse event reporting may result in some missing outcome data. Second, most of the included trials were not specifically designed to monitor the risk of CV events, which might have resulted in incomplete reporting of $\mathrm{CV}$ events. Third, the data used in this analysis were based on the judgment of the investigators, which might result in discrepancies between studies. Despite these limitations, we believe that our analysis adds more positive evidence for CV safety of ICS therapies in COPD patients. We will investigate the intraclass differences in the risk of CV events between different ICS therapies in our future meta-analysis. Our follow-up reanalysis of patient-level data (gender, age, smoking history, pulmonary function, and preexisting ICS use) may clarify the optimal role of ICS use in COPD.

\section{Conclusions}

In summary, despite certain limitations, our findings still have potential implications. We performed a meta-analysis of 31 RCTs, and the outcome indicates that ICSs do not increase the risk of CV events in COPD patients. This analysis also provides further evidence of safety for this important treatment option. Further studies are needed to validate our results in independent cohorts of patients with larger sample sizes and a wider range of clinical courses. 


\section{Conflicts of Interest}

The authors have no conflicts of interest to declare.

\section{Acknowledgments}

The authors thank Miaomiao Hou for her help with data abstraction and Jie Niu for his help with picture processing. This research was supported by a grant from the Natural Science Foundation of China (no. 81470240).

\section{References}

[1] Collaborators GBDCRD, "Global, regional, and national deaths, prevalence, disability-adjusted life years, and years lived with disability for chronic obstructive pulmonary disease and asthma, 1990-2015: a systematic analysis for the Global Burden of Disease Study 2015," The Lancet Respiratory Medicine, vol. 5, pp. 691-706, 2017.

[2] B. N. Mccullagh, A. P. Comellas, Z. K. Ballas, J. J. Newell, M. B. Zimmerman, and A. E. Azar, "Antibody deficiency in patients with frequent exacerbations of chronic obstructive pulmonary disease (COPD)," PLoS One, vol. 12, no. 2, Article ID e0172437, 2017.

[3] M. T. Dransfield, J. Bourbeau, P. W. Jones et al., "Once-daily inhaled fluticasone furoate and vilanterol versus vilanterol only for prevention of exacerbations of COPD: two replicate double-blind, parallel-group, randomised controlled trials," The Lancet Respiratory Medicine, vol. 1, no. 3, pp. 210-223, 2013.

[4] M. Bonay, C. Bancal, and B. Crestani, "Benefits and risks of inhaled corticosteroids in chronic obstructive pulmonary disease," Drog Safety, vol. 25, no. 1, pp. 57-71, 2002.

[5] D. Stolz, H. H. Hirsch, D. Schilter et al., "Intensified therapy with inhaled corticosteroids and LABA at the onset of URTI to prevent COPD exacerbations-a multicentre, randomised, double-blind, placebo-controlled trial," American Journal of Respiratory and Critical Care Medicine, vol. 197, no. 9, pp. 1136-1146, 2017.

[6] C. F. Vogelmeier, G. J. Criner, F. J. Martinez et al., "Global strategy for the diagnosis, management, and prevention of chronic obstructive lung disease 2017 report. GOLD executive summary," Archivos de Bronconeumología, vol. 53, no. 3, pp. 128-149, 2017.

[7] A. V. Gonzalez, J. Coulombe, P. Ernst, and S. Suissa, "Longterm use of inhaled corticosteroids in COPD and the risk of fracture," Chest, vol. 153, no. 2, pp. 321-328, 2017.

[8] P. Ambrosino, R. Lupoli, G. Cafaro et al., "Subclinical carotid atherosclerosis in patients with chronic obstructive pulmonary disease: a meta-analysis of literature studies," Annals of Medicine, vol. 49, no. 6, pp. 513-524, 2017.

[9] S. M. Curkendall, C. DeLuise, J. K. Jones et al., "Cardiovascular disease in patients with chronic obstructive pulmonary disease, Saskatchewan Canada cardiovascular disease in COPD patients," Annals of Epidemiology, vol. 16, no. 1, pp. 63-70, 2006.

[10] D. D. Sin and S. F. Paul Man, "Cooling the fire within: inhaled corticosteroids and cardiovascular mortality in COPD," Chest, vol. 130, no. 3, pp. 629-631, 2006.

[11] D. Pandya, A. Puttanna, and V. Balagopal, "Systemic effects of inhaled corticosteroids: an overview," Open Respiratory Medicine Journal, vol. 8, no. 1, pp. 59-65, 2014.

[12] S. Battaglia, I. Cardillo, F. Lavorini, M. Spatafora, and N. Scichilone, "Safety considerations of inhaled corticosteroids in the elderly," Drugs and Aging, vol. 31, no. 11, pp. 787-796, 2014.

[13] T. A. Lee, A. S. Pickard, D. H. Au, B. Bartle, and K. B. Weiss, "Risk of death associated with medications for recently diagnosed chronic obstructive pulmonary disease," Annals of Internal Medicine, vol. 149, no. 6, pp. 380-390, 2008.

[14] C. Macie, K. Wooldrage, J. Manfreda, and N. R. Anthonisen, "Inhaled corticosteroids and mortality in COPD," Chest, vol. 130, no. 3, pp. 640-646, 2006.

[15] C. G. Lofdahl, D. S. Postma, N. B. Pride, J. Boe, and N. A. Thoren, "Possible protection by inhaled budesonide against ischaemic cardiac events in mild COPD," European Respiratory Journal, vol. 29, no. 6, pp. 1115-1119, 2007.

[16] F. J. Martinez, J. Boscia, G. Feldman et al., "Fluticasone furoate/vilanterol $(100 / 25 ; 200 / 25 \mu \mathrm{g})$ improves lung function in COPD: a randomised trial," Respiratory Medicine, vol. 107, no. 4, pp. 550-559, 2013.

[17] J. Zheng, T. de Guia, J. Wang-Jairaj et al., "Efficacy and safety of fluticasone furoate/vilanterol (50/25 mcg; 100/25 mcg; 200/ $25 \mathrm{mcg}$ ) in Asian patients with chronic obstructive pulmonary disease: a randomized placebo-controlled trial," Current Medical Research and Opinion, vol. 31, no. 6, pp. 1191-1200, 2015.

[18] M. T. Halpern, J. K. Schmier, M. D. Van Kerkhove, M. Watkins, and C. J. Kalberg, "Impact of long-term inhaled corticosteroid therapy on bone mineral density: results of a meta-analysis," Annals of Allergy, Asthma and Immunology, vol. 92, no. 2, pp. 201-207, 2004.

[19] N. Xia, H. Wang, and X. Nie, "Inhaled long-acting $\beta 2$-agonists do not increase fatal cardiovascular adverse events in COPD: a meta-analysis," PLoS One, vol. 10, no. 9, Article ID e0137904, 2015.

[20] C. F. Vogelmeier, G. J. Criner, F. J. Martinez et al., "Global strategy for the diagnosis, management and prevention of chronic obstructive lung disease 2017 report: GOLD executive summary," Respirology, vol. 22, no. 3, pp. 575-601, 2017.

[21] A. R. Jadad, R. Andrew Moore, D. Carroll et al., "Assessing the quality of reports of randomized clinical trials: is blinding necessary?," Controlled Clinical Trials, vol. 17, no. 1, pp. 1-12, 1996.

[22] S. D. Aaron, K. L. Vandemheen, D. Fergusson et al., "Tiotropium in combination with placebo, salmeterol, or fluticasone-salmeterol for treatment of chronic obstructive pulmonary disease: a randomized trial," Annals of Internal Medicine, vol. 146, no. 8, pp. 545-555, 2007.

[23] P. S. Burge, P. M. Calverley, P. W. Jones, S. Spencer, J. A. Anderson, and T. K. Maslen, "Randomised, double blind, placebo controlled study of fluticasone propionate in patients with moderate to severe chronic obstructive pulmonary disease: the ISOLDE trial," BMJ, vol. 320, no. 7245, pp. 1297-1303, 2000.

[24] P. Calverley, R. Pauwels, J. Vestbo et al., "Combined salmeterol and fluticasone in the treatment of chronic obstructive pulmonary disease: a randomised controlled trial," The Lancet, vol. 361, no. 9356, pp. 449-456, 2003.

[25] P. M. Calverley, J. A. Anderson, B. Celli et al., "Salmeterol and fluticasone propionate and survival in chronic obstructive pulmonary disease," New England Journal of Medicine, vol. 356, no. 8, pp. 775-789, 2007.

[26] G. T. Ferguson, A. Anzueto, R. Fei, A. Emmett, K. Knobil, and C. Kalberg, "Effect of fluticasone propionate/salmeterol (250/ $50 \mu \mathrm{g})$ or salmeterol $(50 \mu \mathrm{g})$ on COPD exacerbations," Respiratory Medicine, vol. 102, no. 8, pp. 1099-1108, 2008.

[27] N. A. Hanania, P. Darken, D. Horstman et al., "The efficacy and safety of fluticasone propionate $(250 \mu \mathrm{g}) / \mathrm{salmeterol}$ 
$(50 \mu \mathrm{g})$ combined in the Diskus inhaler for the treatment of COPD," Chest, vol. 124, no. 3, pp. 834-843, 2003.

[28] P. Kardos, M. Wencker, T. Glaab, and C. Vogelmeier, "Impact of salmeterol/fluticasone propionate versus salmeterol on exacerbations in severe chronic obstructive pulmonary disease," American Journal of Respiratory and Critical Care Medicine, vol. 175, no. 2, pp. 144-149, 2007.

[29] P. L. Paggiaro, R. Dahle, I. Bakran, L. Frith, K. Hollingworth, and J. Efthimiou, "Multicentre randomised placebo-controlled trial of inhaled fluticasone propionate in patients with chronic obstructive pulmonary disease," The Lancet, vol. 351, no. 9105, pp. 773-780, 1998.

[30] E. F. Wouters, D. S. Postma, B. Fokkens et al., "Withdrawal of fluticasone propionate from combined salmeterol/fluticasone treatment in patients with COPD causes immediate and sustained disease deterioration: a randomised controlled trial," Thorax, vol. 60, no. 6, pp. 480-487, 2005.

[31] J. A. Boscia, K. K. Pudi, M. T. Zvarich, L. Sanford, S. K. Siederer, and C. Crim, "Effect of once-daily fluticasone furoate/vilanterol on 24-hour pulmonary function in patients with chronic obstructive pulmonary disease: a randomized, three-way, incomplete block, crossover study," Clinical Therapeutics, vol. 34, no. 8, pp. 1655.e5-1666.e5, 2012.

[32] J. Vestbo, J. A. Anderson, P. M. Calverley et al., "Adherence to inhaled therapy, mortality and hospital admission in COPD," Thorax, vol. 64, no. 11, pp. 939-943, 2009.

[33] J. Vestbo, J. A. Anderson, R. D. Brook et al., "Fluticasone furoate and vilanterol and survival in chronic obstructive pulmonary disease with heightened cardiovascular risk (SUMMIT): a double-blind randomised controlled trial," The Lancet, vol. 387, no. 10030, pp. 1817-1826, 2016.

[34] E. M. Kerwin, C. Scott-Wilson, L. Sanford et al., "A randomised trial of fluticasone furoate/vilanterol $(50 / 25 \mu \mathrm{g} ; 100 /$ $25 \mu \mathrm{g}$ ) on lung function in COPD," Respiratory Medicine, vol. 107 , no. 4 , pp. $560-569,2013$.

[35] P. M. Calverley, J. A. Anderson, B. Celli et al., "Cardiovascular events in patients with COPD: TORCH study results," Thorax, vol. 65, no. 8, pp. 719-725, 2010.

[36] J. F. Donohue, S. Worsley, C. Q. Zhu, L. Hardaker, and A. Church, "Improvements in lung function with umeclidinium/vilanterol versus fluticasone propionate/salmeterol in patients with moderate-to-severe COPD and infrequent exacerbations," Respiratory Medicine, vol. 109, no. 7, pp. 870-881, 2015.

[37] D. Singh, S. Worsley, C. Q. Zhu, L. Hardaker, and A. Church, "Umeclidinium/vilanterol versus fluticasone propionate/ salmeterol in COPD: a randomised trial," BMC Pulmonary Medicine, vol. 15, p. 91, 2015.

[38] C. F. Vogelmeier, E. D. Bateman, J. Pallante et al., "Efficacy and safety of once-daily QVA149 compared with twice-daily salmeterol-fluticasone in patients with chronic obstructive pulmonary disease (ILLUMINATE): a randomised, doubleblind, parallel group study," The Lancet Respiratory Medicine, vol. 1, no. 1, pp. 51-60, 2013.

[39] J. Vestbo, D. Leather, N. D. Bakerly et al., "Effectiveness of fluticasone furoate-vilanterol for COPD in clinical practice," New England Journal of Medicine, vol. 375, no. 13, pp. 1253-1260, 2016.

[40] GlaxoSmithKline. Study No. SCO100250.

[41] GlaxoSmithKline. Study No. FLTA3025.

[42] GlaxoSmithKline. Study No. SCO100470.

[43] GlaxoSmithKline. Study No. SCO40041.

[44] GlaxoSmithKline. Study No. SFCT01/SCO30002.

[45] S. I. Rennard, D. P. Tashkin, J. McElhattan et al., "Efficacy and tolerability of budesonide/formoterol in one hydrofluoroalkane pressurized metered-dose inhaler in patients with chronic obstructive pulmonary disease: results from a 1-year randomized controlled clinical trial," Drugs, vol. 69, no. 5, pp. 549-565, 2009.

[46] D. P. Tashkin, S. I. Rennard, P. Martin et al., "Efficacy and safety of budesonide and formoterol in one pressurized metered-dose inhaler in patients with moderate to very severe chronic obstructive pulmonary disease: results of a 6-month randomized clinical trial," Drugs, vol. 68, no. 14, pp. 1975-2000, 2008.

[47] J. Vestbo, T. Søorensen, P. Lange, A. Brix, P. Torre, and K. Viskum, "Long-term effect of inhaled budesonide in mild and moderate chronic obstructive pulmonary disease: a randomised controlled trial," The Lancet, vol. 353, no. 9167, pp. 1819-1823, 1999.

[48] J. A. Wedzicha, D. Singh, J. Vestbo et al., "Extrafine beclomethasone/formoterol in severe COPD patients with history of exacerbations," Respiratory Medicine, vol. 108, no. 8, pp. 1153-1162, 2014.

[49] L. M. Fabbri and K. F. Rabe, "From COPD to chronic systemic inflammatory syndrome?," The Lancet, vol. 370, no. 9589, pp. 797-799, 2007.

[50] J. Vestbo, S. S. Hurd, A. G. Agusti et al., "Global strategy for the diagnosis, management, and prevention of chronic obstructive pulmonary disease: GOLD executive summary," American Journal of Respiratory and Critical Care Medicine, vol. 187, no. 4, pp. 347-365, 2013.

[51] D. M. Mannino, D. Thorn, A. Swensen, and F. Holguin, "Prevalence and outcomes of diabetes, hypertension and cardiovascular disease in COPD," European Respiratory Journal, vol. 32, no. 4, pp. 962-969, 2008.

[52] N. R. Anthonisen, M. A. Skeans, R. A. Wise et al., "The effects of a smoking cessation intervention on 14.5-year mortality: a randomized clinical trial," Annals of Internal Medicine, vol. 142, no. 4, pp. 233-239, 2005.

[53] S. Sidney, M. Sorel, C. P. Quesenberry, C. DeLuise, S. Lanes, and M. D. Eisner, "COPD and incident cardiovascular disease hospitalizations and mortality: Kaiser Permanente Medical Care Program," Chest, vol. 128, no. 4, pp. 2068-2075, 2005.

[54] J. A. Wedzicha, T. A. Seemungal, P. K. MacCallum et al., "Acute exacerbations of chronic obstructive pulmonary disease are accompanied by elevations of plasma fibrinogen and serum IL-6 levels," Thrombosis and Haemostasis, vol. 84, no. 2, pp. $210-215,2000$.

[55] D. D. Sin and S. F. Man, "Why are patients with chronic obstructive pulmonary disease at increased risk of cardiovascular diseases? The potential role of systemic inflammation in chronic obstructive pulmonary disease," Circulation, vol. 107, no. 11, pp. 1514-1519, 2003.

[56] J. D. Maclay, D. A. McAllister, N. L. Mills et al., "Vascular dysfunction in chronic obstructive pulmonary disease," American journal of Respiratory and Critical Care Medicine, vol. 180, no. 6, pp. 513-520, 2009.

[57] P. J. Barnes and B. R. Celli, "Systemic manifestations and comorbidities of COPD," European Respiratory Journal, vol. 33, no. 5, pp. 1165-1185, 2009.

[58] D. E. Sholter and P. W. Armstrong, "Adverse effects of corticosteroids on the cardiovascular system," Canadian Journal of Cardiology, vol. 16, no. 4, pp. 505-511, 2000.

[59] D. D. Sin, S. F. Man, D. D. Marciniuk et al., "The effects of fluticasone with or without salmeterol on systemic biomarkers of inflammation in chronic obstructive pulmonary disease," American Journal of Respiratory and Critical Care Medicine, vol. 177, no. 11, pp. 1207-1214, 2008.

[60] P. M. Calverley, W. Boonsawat, Z. Cseke, N. Zhong, S. Peterson, and H. Olsson, "Maintenance therapy with 
budesonide and formoterol in chronic obstructive pulmonary disease," European Respiratory Journal, vol. 22, no. 6, pp. 912-919, 2003.

[61] Y. K. Loke, C. S. Kwok, and S. Singh, "Risk of myocardial infarction and cardiovascular death associated with inhaled corticosteroids in COPD," European Respiratory Journal, vol. 35 , no. 5, pp. 1003-1021, 2010 .

[62] L. Huiart, P. Ernst, X. Ranouil, and S. Suissa, "Low-dose inhaled corticosteroids and the risk of acute myocardial infarction in COPD," European Respiratory Journal, vol. 25, no. 4 , pp. 634-639, 2005. 


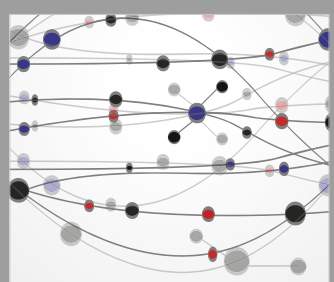

The Scientific World Journal
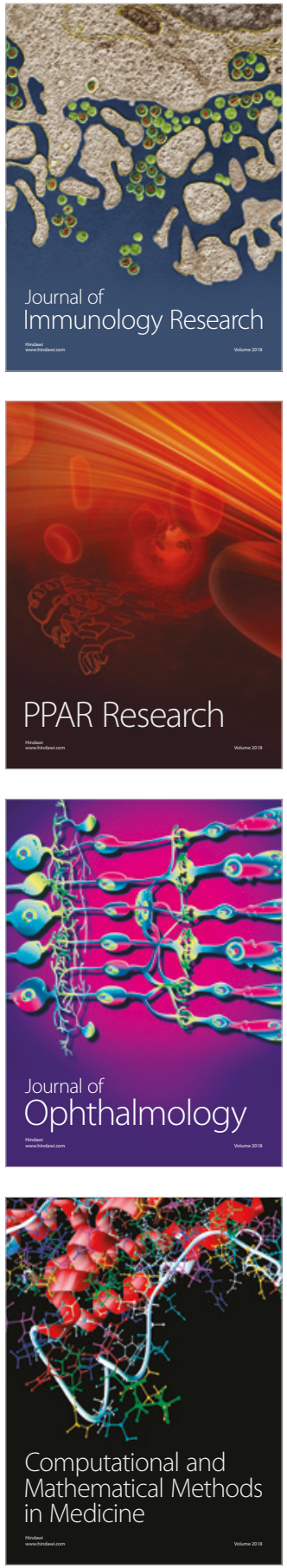

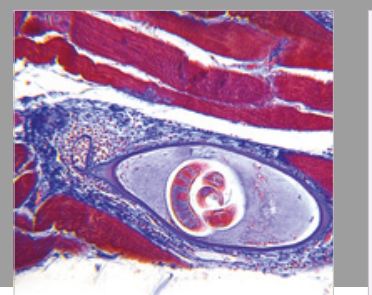

Gastroenterology Research and Practice

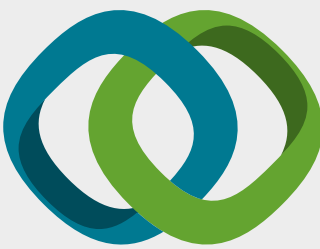

\section{Hindawi}

Submit your manuscripts at

www.hindawi.com
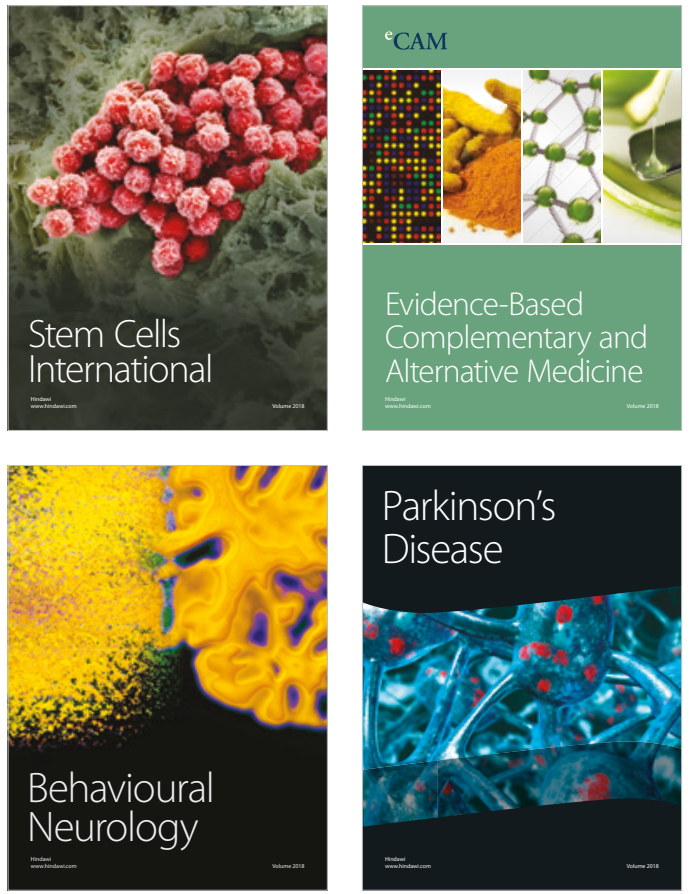

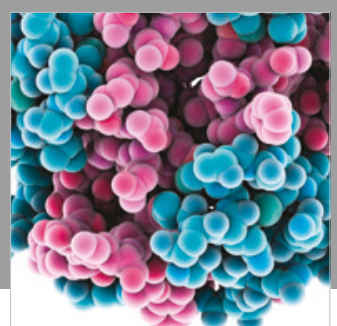

ournal of

Diabetes Research

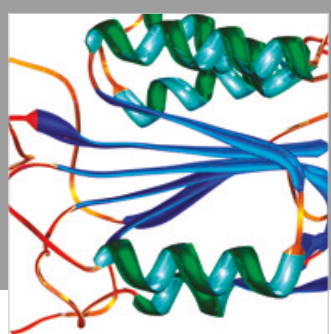

Disease Markers
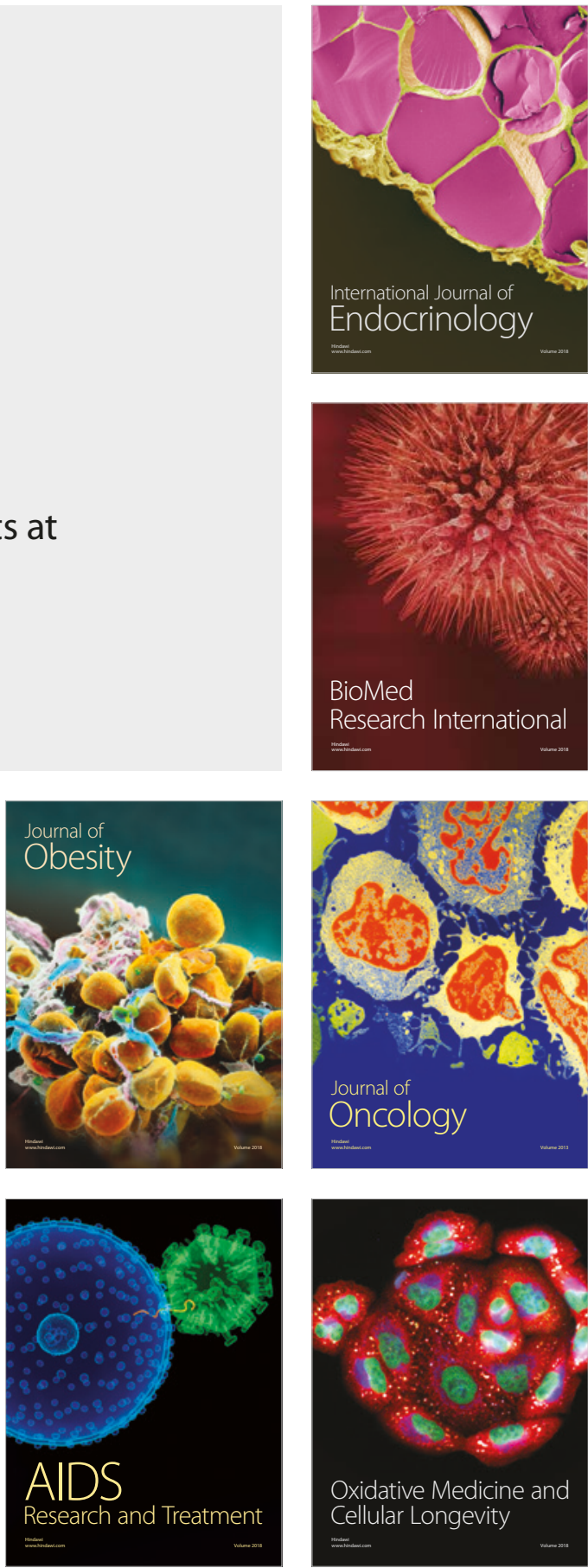